\title{
NEUROPATÍA AUTONÓMICA DIABÉTICA: MANIFESTACIONES CLÍNICAS POCO CONOCIDAS
}

\author{
DIABETIC AUTONOMIC NEUROPATHY: \\ LITTLE KNOWN CLINICAL MANIFESTATIONS
}

\author{
Carolina Domínguez ${ }^{1,10}$, Claudia Flores ${ }^{2,10}$, Graciela Fuente ${ }^{3,10}$, Concepción García ${ }^{4,10}$, \\ Marcela Giménez Rey ${ }^{5,10}$, Fernanda Huber ${ }^{6,10}$, Solange Houssay ${ }^{7,10}$, Maricel Recalde ${ }^{8,10}$, Raquel Urdaneta ${ }^{9,10}$
}

\section{RESUMEN}

La neuropatía crónica es la complicación más prevalente de la diabetes. De las distintas formas de neuropatía diabética, la polineuropatía distal y simétrica y la neuropatía autonómica, particularmente la neuropatía autonómica cardíaca, son las más estudiadas y en ocasiones son asintomáticas.

Los pacientes con prediabetes también pueden desarrollar neuropatías similares a la neuropatía diabética. La prevención es un componente clave en la atención de estas complicaciones.

La neuropatía autonómica diabética afecta varios órganos y sistemas de la economía. Nuestro objetivo es describir aquellas manifestaciones clínicas poco conocidas, y en consecuencia poco tenidas en cuenta, que afectan el sistema cardiovascular, el gastrointestinal y el compromiso vesical.

Palabras clave: diabetes; neuropatía autonómica; cardiovascular; gastrointestinal; disfunción vesical.

Revista de la Sociedad Argentina de Diabetes 2018; Vol. 52 (48-64)

\section{ABSTRACT}

Chronic neuropathy is the most prevalent of the diabetic complications. Distal and symmetric sensitive polyneuropathy, and autonomic compromise, particularly cardiac autonomic neuropathy, are the most studied; occasionally they are asymptomatic. Like diabetic patients, prediabetics can also develop neuropathy. Prevention is a key component in these complications. Autonomic neuropathy affects several body's organs and systems. Our goal is to describe those less known clinical manifestations, and because of this, less considered complications that affect cardiovascular, gastrointestinal system and bladder functioning.

Key words: diabetes; autonomic neuropathy; cardiovascular; gastrointestinal; bladder dysfunction.

Revista de la Sociedad Argentina de Diabetes 2018; Vol. 52 (48-64)
1 Médica especialista en Medicina Interna y Nutrición, Magister en Diabetes, Hospital General de Agudos Carlos G. Durand, Ciudad Autónoma de Buenos Aires, Argentina

2 Médica especialista en Medicina Interna y Endocrinología, Hospital Interzonal General Dr. José Penna, Bahía Blanca, Provincia de Buenos Aires, Argentina

3 Médica especialista en Nutrición, especializada en Diabetes, Jefa de la Unidad de Nutrición del Hospital General de Agudos Carlos G. Durand, Ciudad Autónoma de Buenos Aires, Argentina

4 Médica especialista en Medicina Interna y Nutrición, especializada en Diabetes, Hospital General de Agudos Carlos G. Durand, Ciudad Autónoma de Buenos Aires, Argentina

5 Médica especialista en Medicina Interna y Nutrición, Hospital Gobernador Domingo Mercante, José C. Paz, Provincia de Buenos Aires, Argentina

6 Médica especialista en Medicina Interna, especializada en Diabetes, Hospital General de Agudos Carlos G. Durand, Ciudad Autónoma de Buenos Aires, Argentina
7 Médica especialista en Medicina Interna y Nutrición, especializada en Diabetes, Clínica San Camilo, Ciudad Autónoma de Buenos Aires, Argentina

8 Médica especialista en Medicina Interna y Nutrición, especializada en Diabetes, Hospital Británico, Ciudad Autónoma de Buenos Aires, Argentina

9 Médica especialista en Nutrición, Hospital General de Agudos Carlos G. Durand, Ciudad Autónoma de Buenos Aires, Argentina

10 Comité de Neuropatía Diabética de la Sociedad Argentina de Diabetes 2017

Contacto de la autora: Raquel Urdaneta Vélez

E-mail: raquelurdaneta@live.com.ar Correspondencia: Salguero 2077 (C1425DEE), Ciudad Autónoma de Buenos Aires, Argentina Fecha de trabajo recibido: 13/07/18

Fecha de trabajo aceptado: 29/07/2018

Conflictos de interés: las autoras declaran que no existe conflicto de interés 


\section{INTRODUCCIÓN}

La neuropatía crónica es la complicación más prevalente de la diabetes. Este grupo heterogéneo de condiciones afecta diferentes partes del sistema nervioso y presenta distintas manifestaciones clínicas. El reconocimiento temprano y el manejo apropiado de la misma en el paciente con diabetes son importantes por las siguientes consideraciones:

- La neuropatía diabética es un diagnóstico de exclusión. Las neuropatías no diabéticas pueden estar presentes en el paciente diabético y deben recibir tratamiento específico.

- Mayormente puede ser asintomática y/o demostrar síntomas no específicos en estadios tempranos que no son reconocidos adecuadamente; cerca del $50 \%$ de las neuropatías diabéticas puede ser asintomática. Si no son reconocidas y los cuidados preventivos no se implementan de forma adecuada, los pacientes se encuentran en riesgo de padecer serias consecuencias clínicas.

- El diagnóstico y el tratamiento de la neuropatía autonómica permiten mejorar los síntomas, reducir las secuelas y optimizar la calidad de vida.

- Existen varias opciones terapéuticas para esta complicación.

De las formas de neuropatía diabética (ND), la po- lineuropatía distal y simétrica (PDS) y la neuropatía autonómica (NA), particularmente la neuropatía autonómica cardíaca (NAC), son las más estudiadas. Existen también manifestaciones atípicas de ND.

Los pacientes con prediabetes también pueden desarrollar neuropatías similares a la ND11. La prevención es un componente clave en la atención de estas complicaciones. Como la evidencia más robusta en relación al tratamiento de la ND pertenece a la PDS y a la NA, es necesario detectar los estadios más precoces para permitir una intervención terapéutica temprana².

La NA es considerada una complicación seria, frecuentemente subestimada y habitualmente asintomática o con síntomas inespecíficos sobre todo en estadios tempranos ${ }^{3}$. La afectación del sistema nervioso autonómico compromete al comienzo el sistema nervioso parasimpático y posteriormente el sistema simpático lo que provoca de esta forma que las manifestaciones clínicas varíen a lo largo de la evolución.

La neuropatía autonómica diabética afecta a varios órganos y sistemas de la economía entre los cuales se describirá el sistema cardiovascular, el gastrointestinal y dentro del genitourinario se resaltará el compromiso vesical dado que la disfunción sexual fue publicada anteriormente ${ }^{4}(\text { Tabla } 1)^{2}$.

\begin{tabular}{|c|c|c|c|}
\hline NAC & Gastrointestinal (GI) & Urogenital & Sudomotor \\
\hline Taquicardia de reposo & Gastroparesia & Disfunción vesical & Piel seca \\
\hline Regulación anormal de la tensión arterial & Náusea & Frecuencia & Anhidrosis \\
\hline Patrón nondipper & Vómitos & Urgencia & Sudoración gustatoria \\
\hline \multirow[t]{7}{*}{ Dipper inverso } & Pérdida del apetito & Nocturia & \\
\hline & Saciedad temprana & Sensación miccional & \\
\hline & Vómitos postprandiales & Esfuerzo miccional & \\
\hline & Diabetes lábil & Chorro débil & \\
\hline & & Incontinencia urinaria & \\
\hline & & Retención urinaria & \\
\hline & & Goteo miccional & \\
\hline $\begin{array}{l}\text { Hipotensión ortostática } \\
\text { (con cambio de posición) }\end{array}$ & Disfunción esofágica & Disfunción sexual masculina & \\
\hline Vértigo & Ardor retroesternal & Disfunción eréctil & \\
\hline Mareos & Disfagia para sólidos & Disminución de la líbido & \\
\hline Debilidad & & Eyaculación anormal & \\
\hline \multicolumn{4}{|l|}{ Fotopsia } \\
\hline \multicolumn{4}{|l|}{ Alteraciones visuales } \\
\hline \multicolumn{4}{|l|}{ Síncope } \\
\hline $\begin{array}{l}\text { Taquicardia o bradicardia ortostáticas e } \\
\text { incompetencia cronotrópica }\end{array}$ & Diarrea diabética & Disfunción sexual femenina & \\
\hline Náuseas & Diarrea profusa y líquida & Disminución del deseo sexual & \\
\hline Vértigo & Incontinencia fecal & Dispareunia & \\
\hline Mareos & Puede alternar con constipación & Lubricación inadecuada & \\
\hline Debilidad & & Disminución de excitación & \\
\hline \multicolumn{4}{|l|}{ Fotopsia } \\
\hline \multicolumn{4}{|l|}{ Alteraciones visuales } \\
\hline \multicolumn{4}{|l|}{ Síncope } \\
\hline \multirow[t]{2}{*}{ Intolerancia al ejercicio } & Constipación & & \\
\hline & Puede alternar con diarrea explosiva & & \\
\hline
\end{tabular}

Tabla 1: Signos y síntomas asociados a la NA². 


\section{1) Neuropatía autonómica cardíaca}

La neuropatía autonómica cardíaca (NAC) se produce por el daño de las fibras nerviosas que inervan el corazón y los vasos sanguíneos que resulta en anormalidades en el control de la frecuencia cardíaca y la dinámica vascular. La NAC es una importante causa de morbimortalidad asociada al elevado riesgo de arritmias cardíacas y muerte súbita ${ }^{5}$.

\section{Epidemiología}

Aunque la prevalencia de NAC es muy baja en pacientes de reciente diagnóstico con diabetes tipo 1 (DM1), la misma aumenta sustancialmente a medida que se incrementa la duración de la DM. En la cohorte de Diabetes Control and Complications Trial/Epidemiology of Diabetes Interventions and Complications Study (DCCT/EDIC), luego de 20 años de evolución de la enfermedad, se observó al menos un 30\% de prevalencia. En la diabetes tipo 2 (DM2), la prevalencia puede aumentar con la duración de la DM y presentarse en más del $60 \%$ de los pacientes luego de 15 años de diagnóstico.

La NAC puede afectar a jóvenes, especialmente mujeres, y aquellas con niveles altos de hemoglobina glicosilada $\mathrm{A} 1 \mathrm{c}$, con una prevalencia de al menos $20 \%$, tanto en DM1 como DM2 ${ }^{6}$. También puede presentarse en pacientes con tolerancia a la glucosa alterada, insulinorresistencia y síndrome metabólico'.

El diagnóstico oportuno de la NAC puede tener implicancias clínicas dado que se trata de un factor de riesgo independiente para mortalidad cardiovascular, arritmia, isquemia silente, cualquier evento cardiovascular mayor y disfunción miocárdica ${ }^{78,9}$.

\section{Manifestaciones clínicas y fisiopatología}

- Taquicardia de reposo y frecuencia cardíaca fija. Son manifestaciones tardías en los pacientes con DM y afectación vagal (parasimpática). La frecuencia cardíaca (FC) oscila entre 90 y 100 latidos por minuto (LpM) y ocasionalmente alcanza los 130 LpM. Las FC más elevadas se encuentran más tempranamente en los pacientes ya que se debe al daño parasimpático que ocurre antes que el daño simpático. En la evolución de la neuropatía, cuando se produce el daño simpático, la FC regresa a valores normales pero altos. La FC fija que no responde al ejercicio moderado, al estrés o al sueño indica una denervación cardíaca casi completa ${ }^{10}$.
- Intolerancia al ejercicio. La NAC reduce la respuesta de la FC y la tensión arterial al ejercicio y el incremento del gasto cardíaco durante el mismo. Estos pacientes requieren evaluación cardiológica previa a la indicación de la actividad física, solicitando test de estrés cardíaco. No es suficiente realizar solamente un electrocardiograma.

- Inestabilidad cardiovascular intraoperatoria. La morbimortalidad cardiovascular se incrementa de dos a tres veces en pacientes con DM. Los pacientes con NAC presentan mayor descenso de la FC y de la tensión arterial (TA) durante la inducción anestésica con menor aumento durante la intubación y la extubación; es por ello que requieren mayor soporte vasopresor. La respuesta autonómica normal a la vasoconstricción y la taquicardia no están completamente compensadas por los efectos vasodilatadores de la anestesia. Existe asociación entre NAC e hipotermia intraoperatoria severa, que resulta en la disminución del metabolismo de las drogas y en el retraso en la curación de las heridas.

- Hipotensión ortostática. Se define como la caída de la TA mayor o igual a $20 \mathrm{mmHg}$ en TA sistólica o mayor o igual a $10 \mathrm{mmHg}$ en TA diastólica, en respuesta a un cambio postural al ir de la posición supina a posición de pie. Los síntomas incluyen: debilidad, mareos, náuseas, alteraciones visuales, incluso síncope. La hipotensión ortostática puede ser discapacitante o bien pasar inadvertida.

- Síndromes de taquicardia y bradicardia postural ortostática (STPO) (SBPO). Los síntomas compatibles con ortostatismo como mareos, náuseas, parestesias periorales y cefalea pueden ocurrir ante el cambio de posición supina a posición de pie; pueden ser causados por el STPO, taquicardia sinusal, síncope neurocardiogénico y las anormalidades de la función de los barorreceptores. Ante el cambio de posición se produce taquicardia o bradicardia en ausencia de la caída de la TA.

La patogénesis del STPO es oscura. Algunos pacientes tienen algún defecto en la vasoconstricción periférica con aumento del flujo sanguíneo a nivel de la pantorrilla, mientras que otros manifiestan aumento de la resistencia vascular periférica y disminución del flujo sanguíneo ${ }^{11}$.

EI STPO se asocia a un defecto selectivo en las fibras nerviosas intraepidérmicas. Las concentraciones de norepinefrina se relacionan con la severidad de la neuropatía autonómica y con la 
pérdida del tono de las fibras simpáticas $C$, lo que se traduciría en un inadecuado retorno venoso e hipovolemia torácica. Estos pacientes no tienen cambios en la actividad de la renina plasmática y baja aldosterona, lo que les confiere una marcada reducción en el volumen plasmático. También presentan marcada reducción en la eritropoyetina plasmática sugiriendo que el riñón juega un rol en la patogénesis de esta condición ${ }^{12}$.

Además en algunos pacientes con síntomas de ortostatismo que tienen bradicardia paradojal en la posición de pie, los síntomas pueden asemejarse a los de la hipotensión. Es importante reconocer esta diferencia dado que cada uno de estos cuadros es pasible de recibir un tratamiento sencillo ${ }^{13}$.

- Infarto agudo de miocardio (IAM) silente y síndrome de denervación cardíaca. La disminución de la percepción del dolor isquémico puede retrasar el reconocimiento del IAM y por lo tanto demorar la terapia apropiada. La signo-sintomatología que orienta a pensar en un IAM en contexto de un paciente con NAC incluye: tos, náuseas, vómitos, disnea, cansancio y cambios en el electrocardiograma ${ }^{10}$.

- Incremento del riesgo de mortalidad. Algunos estudios muestran un incremento de dos a tres veces del riesgo de NAC en pacientes que manifiestan intervalo QT prolongado, pudiéndose especular que la NAC predispone a arritmias ventriculares malignas y muerte súbita por paro cardíaco como en el síndrome de QT prolongado.

- Cardiopatía autonómica. La NAC puede asociarse a anormalidades diastólicas del ventrículo izquierdo y en ausencia de enfermedad cardíaca en pacientes con diabetes. Estudios ecocardiográficos demostraron una correlación significativa entre la severidad de la NAC y la reducción del pico de llenado diastólico con un aumento de la contribución atrial a dicho llenado. Es difícil evaluar si la NAC es un factor independiente asociado a la disfunción ventricular izquierda dado que otros factores pueden estar involucrados como es el caso de la fibrosis miocárdica intersticial o la microangiopatía. La NAC se asocia con la disfunción diastólica del ventrículo izquierdo en reposo, tanto en individuos con DM2 de larga data como con DM1. La disfunción diastólica del ventrículo izquierdo (VI) puede progresar a insuficiencia cardíaca con preservación de la función sistólica del VI (insuficiencia cardíaca diastólica), la cual se relacionaría con una alta tasa de morbimortalidad. La fisiopatología de la disfunción diastólica del VI incluye el retraso en la relajación, alteración del llenado ventricular y/o aumento de la resistencia ${ }^{14}$.

\section{Diagnóstico}

En las etapas tempranas, la NAC puede ser totalmente asintomática y detectarse sólo por la disminución de la variabilidad de la frecuencia cardíaca ante una respiración profunda ${ }^{15,16}$. Los síntomas más frecuentes de NAC pueden ocurrir al ponerse en posición de pie e incluyen mareos, debilidad, palpitaciones, desmayos y síncope. Los mismos pueden presentarse tardíamente en el curso de la enfermedad ${ }^{17,18}$. Ante la falta de percepción a las hipoglucemias es importante buscar la presencia de NAC dado que ambos cuadros pueden asociarse ${ }^{19}$.

La variabilidad de la FC puede evaluarse en el consultorio ya sea mediante la realización de un electrocardiograma en el momento en que el paciente se para desde la posición de sentado o bien durante 1-2 minutos de una respiración profunda ${ }^{16,19}$.

En casos más avanzados, el paciente puede presentar taquicardia de reposo (mayor de 100 LpM) e intolerancia al ejercicio (170 LpM); también puede asociarse hipotensión ortostática, fácilmente detectable en el consultorio. En la mayoría de los casos de NAC, no hay aumento compensatorio en la FC a pesar de la hipotensión ${ }^{20}$.

Entre los signos y síntomas de NAC se incluyen alteración de la variabilidad de la FC, incremento de la FC de reposo y presencia de hipotensión ortostática. Es preciso tener en cuenta que ante un paciente con historia de pobre control glucémico y sintomatología clara de NAC no es necesario realizar test adicionales ${ }^{2}$. Es importante excluir la presencia de otras comorbilidades o fármacos que puedan imitar la $\mathrm{NAC}^{19,21}(\text { Tabla } 2)^{2}$. 


\begin{tabular}{|c|c|c|c|}
\hline & Síntomas & Signos/pruebas diagnósticas & Diagnóstico diferencial \\
\hline $\begin{array}{l}\text { Taquicardia de } \\
\text { reposo }\end{array}$ & $\begin{array}{l}\text { Palpitaciones } \\
\text { Puede ser asintomática }\end{array}$ & Examen físico: FC>100 & $\begin{array}{l}\text { Anemia } \\
\text { Hipotiroidismo } \\
\text { Fiebre } \\
\text { Enfermedad cardiovascular (fibrilación auricular, etc.) } \\
\text { Deshidratación } \\
\text { Insuficiencia supraadrenal } \\
\text { Agentes simpaticomiméticos } \\
\text { Agentes que contengan efedrina o pseudoefedrina } \\
\text { Suplementos dietarios (alcaloides de la efedrina) } \\
\text { Tabaco, alcohol, cafeína } \\
\text { Cocaína, anfetaminas, etc. }\end{array}$ \\
\hline $\begin{array}{l}\text { Hipotensión } \\
\text { ortostática }\end{array}$ & $\begin{array}{l}\text { Mareos } \\
\text { Debilidad } \\
\text { Palpitaciones } \\
\text { Desmayos } \\
\text { Síncope }\end{array}$ & $\begin{array}{l}\text { Examen físico: caída de } \\
>20 \mathrm{mmHg} \text { TAS } \\
>10 \mathrm{mmHg} \text { TAD }\end{array}$ & $\begin{array}{l}\text { Insuficiencia adrenal } \\
\text { Depleción del volumen intravascular } \\
\text { Hemorragia/anemia aguda } \\
\text { Deshidratación } \\
\text { Embarazo/postparto } \\
\text { Arritmias } \\
\text { Falla cardíaca } \\
\text { Miocarditis } \\
\text { Pericarditis } \\
\text { Enfermedad valvular } \\
\text { Alcohol } \\
\text { Fármacos (antiadrenérgicos, antianginosos, } \\
\text { antiarrítmicos, anticolinérgicos, diuréticos, IECA, } \\
\text { bloqueantes AT1, narcóticos, neurolépticos, sedativos). }\end{array}$ \\
\hline
\end{tabular}

Tabla 2: Diagnóstico².

\section{Recomendaciones ${ }^{2}$}

- Optimizar el control glucémico tan pronto como sea posible para prevenir o retrasar el desarrollo de polineuropatía distal y simétrica, y la neuropatía autonómica en personas con DM1.

- Optimizar el control glucémico para prevenir o retrasar la progresión de la polineuropatía distal y simétrica en personas con DM2.

- Considerar un enfoque multifactorial teniendo a la glucemia como factor de riesgo principal para prevenir la neuropatía autonómica cardíaca en personas con DM2.

- En pacientes con complicaciones microvasculares y neuropáticas es preciso buscar signos y síntomas de NAC.

- En presencia de signo-sintomatología de NAC deben realizarse test que permitan excluir otras comorbilidades o interacciones farmacológicas que puedan imitar a la NAC.

- Debe considerarse la búsqueda de signosintomatología de NAC en pacientes con falta de percepción a la hipoglucemia.

\section{Tratamiento sintomático de la hipotensión ortostática}

El tratamiento de la hipotensión ortostática es un desafío y generalmente involucra intervenciones farmacológicas y no farmacológicas. Debe promoverse la realización de actividad física, dado que la falta de entrenamiento exacerba la intolerancia ortostática. Es importante reponer el volumen con líquidos y sal. La fludrocortisona en bajas dosis puede ser beneficiosa al momento de suplementar la repleción de volumen en algunos pacientes, aunque preocupa el riesgo de hipertensión supina.

Como la hipotensión ortostática de origen neurogénico es en gran parte consecuencia de la falla en la liberación de norepinefrina por parte de las neuronas simpáticas, la administración de fármacos simpaticomiméticos es crucial en el cuidado de los pacientes cuyos síntomas no son controlados con otras medidas ${ }^{20}$.

El midodrine -un agonista selectivo, directo, periférico, del adrenoreceptor $\alpha 1$ - fue aprobado por la Food and Drug Administration (FDA) para el tratamiento de la hipotensión ortostática ${ }^{22}$. Este fármaco debe ser titulado gradualmente hasta obtener eficacia.

Recientemente droxidopa fue aprobado por la FDA para el tratamiento de la hipotensión ortostática de origen neurogénico pero no específicamente para pacientes con esta complicación secundaria a diabetes ${ }^{23}$.

Como conclusión es importante destacar las siguientes consideraciones sobre NAC:

- Puede detectarse al momento del diagnóstico. 
- Ni la edad ni el tipo de diabetes son factores limitantes en su aparición.

- El pobre control glucémico juega un rol central en la patogénesis.

- El tratamiento intensivo puede enlentecer la progresión y retrasar la aparición de anormalidades en los test autonómicos funcionales.

- La neuropatía autonómica subclínica puede detectarse tempranamente utilizando los test de funcionalidad autonómica.

- Las alteraciones autonómicas que se asocian con disfunción del sistema nervioso simpático son complicaciones relativamente tardías de la DM.

- Existe asociación entre la neuropatía autonómica y la nefropatía que contribuye a las altas tasas de mortalidad.

- Los signos y síntomas de la NA no siempre progresan. Esto muestra la necesidad de realizar test autonómicos funcionales para detectar aquellos pacientes con riesgo incrementado de muerte prematura.

- La prevalencia y la tasa de mortalidad pueden ser mayores en individuos con DM2 posiblemente por la larga duración de las anormalidades metabólicas antes del diagnóstico.

\section{2) Neuropatía diabética gastrointestinal}

El compromiso gastrointestinal es común en los pacientes diabéticos; más del 75\% manifiesta síntomas gastrointestinales significativos que afectan desde el esófago hasta la región anorectal ${ }^{24,25}$. La patogénesis de las anormalidades gastrointestinales (GI) es de naturaleza compleja y multifactorial (disfunción motora, neuropatía autonómica, control glucémico, factores psicosociales, medicaciones) e involucra mecanismos reversibles e irreversibles que aún no están bien comprendidos.

Se ha descripto un número de condiciones clínicas que afectan a diferentes segmentos del tracto digestivo en pacientes con NA: dismotilidad esofágica, dismotilidad y enlentecimiento gástrico, dismotilidad y enlentecimiento del tránsito intestinal, sobrecrecimiento bacteriano y diarrea tanto del intestino delgado como grueso.

Existen pocos estudios que hayan investigado la función sensitiva visceral en DM y demostraron anormalidades en los umbrales de percepción en el tono vagal y en los potenciales evocados cerebrales en pacientes con NA. Esto indica que los cambios neuronales relacionados con la diabetes podrían ubicarse tanto en el sistema nervioso periférico como en el central.

Los síntomas más frecuentes como disfagia, ardor o dolor retroesternal, saciedad precoz, reflujo, constipación, dolor abdominal, náuseas, vómitos y diarrea podrían ser severos y afectar la calidad de vida ${ }^{25}$. Puede ocurrir que la afectación neuropática sea asintomática y obligue a su búsqueda ${ }^{26}$.

\section{Fisiopatología}

La actividad del tracto digestivo se regula en función de su contenido; los estímulos fisiológicos inducen reflejos modulatorios que controlan la función digestiva de manera que la digestión normalmente no es percibida. Sin embargo en ciertas circunstancias, los estímulos digestivos podrían activar aferentes sensitivos y originar sensaciones conscientes; tanto las señales reflejas como sensitivas son moduladas mediante un balance de mecanismos inhibitorios y excitatorios. Las personas con diabetes podrían desarrollar neuropatía que afecte el control de la función motora y sensitiva gastrointestinal.

La NA puede comprometer el control de la motilidad intestinal y originar diversos síntomas como diarrea, constipación, distensión intestinal y dolor abdominal. La NA también puede afectar las fibras sensitivas del intestino y, según la vía involucrada, la percepción puede estar aumentada y/o reducida.

\section{Esófago}

El compromiso del tránsito esofágico fue descripto en DM1 y DM2. Las manifestaciones más frecuentes son acidez, disfagia y dolor torácico. La disfagia es el síntoma más característico causado por desórdenes de la motilidad, sin embargo la causa más frecuente de disfagia son las obstrucciones mecánicas por tumores o estenosis. En el caso de dolor torácico, debe excluirse la enfermedad coronaria o causas de otro origen.

El tránsito esofágico se encuentra enlentecido en el $50 \%$ de los pacientes con diabetes de larga duración; el tránsito retrasado refleja falla peristáltica $u$ ondas de presión focales de baja amplitud $^{27,28,29}$. Se encuentran anormalidades en la manometría esofágica en el $50 \%$ de los pacientes. La menor amplitud de la presión del esfínter esofágico inferior (EEI) se relaciona con la prevalencia aumentada de reflujo gastroesofágico en la DM. Recientemente se estudiaron las alteraciones en 
la actividad contráctil evocada mediante la colocación de un balón por ultrasonido que demuestra híper reactividad e incoordinación en las contracciones esofágicas en pacientes con DM.

\section{Estómago}

Durante el ayuno el estómago está contraído y se relaja para acomodarse a los alimentos. Luego de la ingesta, el estómago progresivamente vuelve a contraerse y esta contracción produce el vaciado gástrico progresivo. El compromiso de las vías excitatorias afecta su contracción y resulta en el retraso del vaciado gástrico con posterior aparición de vómitos de la ingesta retenida; por otro lado, la alteración de las vías neurales inhibitorias produce una alteración de la relajación de la pared gástrica en respuesta a una comida y esta mayor tensión de la pared puede generar saciedad pre$\mathrm{COz}$, sensación de plenitud postprandial, distensión abdominal y náuseas. Es necesario tener en cuenta que la variabilidad glucémica debe ser un indicio de sospecha de gastroparesia.

El compromiso gástrico, y específicamente la gastroparesia, se conoce desde hace muchos años; entre el 30 y el $50 \%$ de los pacientes con DM de larga data presentan retraso en el vaciado gástrico que se relaciona con la retención de los alimentos sólidos o líquidos en el estómago proximal y distal, y motilidad anormal de la pared gástrica. En modelos animales se observó tanto enlentecimiento como vaciado rápido.

El control metabólico es de suma importancia en el vaciado gástrico dado que la hiperglucemia marcada enlentece la motilidad GI y la hipoglucemia la acelera.

Como en el resto del tubo digestivo, deben excluirse las causas por obstrucción por tumores y enfermedades ulcerosas, anormalidades metabólicas como la cetoacidosis diabética o urémica y efectos adversos de fármacos.

Los trastornos en la actividad contráctil gástrica pueden evaluarse mediante manometría y estudios de vaciamiento gástrico con gammagrafía. Las anormalidades que pueden detectarse incluyen tres aspectos: disminución del complejo motor interdigestivo (CMMI), reducción de la frecuencia y amplitud de las contracciones en el periodo postprandial, y dismotilidad pilórica ${ }^{30,31}$.

Existen otros estudios descriptos no estandarizados como el Test de Carbono 13 (C13) espirado y ecografía gástrica para medición de liquidos ${ }^{32}$.

\section{Intestino}

Como en el estómago, la actividad del intestino está determinada por su contenido. El intestino maneja su contenido mediante diferentes clases de contracciones anulares que según su patrón temporo espacial producen segmentación, mezclado o propulsión del contenido. La organización de la actividad contráctil intestinal es pobremente conocida. Los síntomas (diarrea, constipación, distensión intestinal, incontinencia fecal o dolor abdominal) pueden presentarse de forma simultánea o alternada.

Luego de descartar patología intestinal mediante los métodos de diagnóstico como ecografía abdominal o videoendoscopía digestiva alta y baja, puede evaluarse el estado funcional del intestino con técnicas más complejas y sólo disponibles en centros especializados ${ }^{32,33}$.

\section{Evaluación de la función intestinal: estudios de motilidad}

- Manometría intestinal. La manometría intestinal (MI) es la técnica patrón oro actual para evaluar la motilidad intestinal. Básicamente consiste en la introducción de sensores de presión montados en un tubo que se introduce en el intestino a través de la boca o el ano para evaluar el intestino delgado o el colon respectivamente. La evaluación de la motilidad intestinal se basa exclusivamente en el patrón de contracciones intestinales, sensadas por el sistema de registro; no mide otros signos de disfunción intestinal motora como el tono o el tránsito del quimo, siendo esto una limitación del método pero con una alta especificidad para cuadros graves.

- Estudio de imágenes endoluminales.

- Videoendoscopía por endocápsula: es la incorporación de una cápsula que incorpora una cámara con flash que una vez ingerida toma fotos secuenciales de la luz intestinal; las imágenes se trasmiten a un grabador externo y se visualizan como un video utilizando un programa de computación que determina si existen alteraciones de la motilidad hipo o híper dinámicas. Tiene la ventaja de no ser invasivo pero no es cuantitativo ${ }^{34,35}$.

- Tomografía computada: se realiza el estudio de imágenes de medición del volumen del gas intestinal retenido por TC.

\section{Evaluación de la función sensitiva gastrointestinal}

La neuropatía digestiva en la diabetes podría afectar también los nervios sensitivos. La percep- 
ción de las señales del intestino depende de la estimulación de receptores en la pared intestinal que activan vías aferentes sensitivas que conducen señales a la corteza cerebral. Las señales aferentes pueden ser moduladas a varios niveles entre la pared del tubo digestivo y el cerebro. Según las vías afectadas por la NA, la percepción puede verse aumentada y resultar en un estado de hipersensibilidad donde los estímulos que no son normalmente percibidos inducen dolor u otros síntomas GI (allodinia). Por el contrario, la NA intestinal puede reducir la percepción e inducir hiposensibilidad. Algunos pacientes desarrollan anestesia visceral y por lo tanto tienen síntomas leves o son asintomáticos ante condiciones abdominales agudas como diverticulitis complicada.

- Test sensitivos. La sensibilidad GI puede estudiarse mediante estímulos con sondas que activan vías aferentes sensitivas. Históricamente se han realizado pruebas de distensión con balón. Las vísceras huecas contienen receptores de tensión que son sensibles a la distensión y producen percepción consciente. Usando una sonda con balón inflable la sensación Gl puede medirse en cualquier punto del intestino. El principal limitante de estas pruebas es la falta de umbrales estandarizados para el diagnóstico de híper o hiposensibilidad. Para estudios de investigación se emplearon estímulos térmicos y químicos para evaluar la sensibilidad viscera ${ }^{36,37,38}$.

- Test de hidrógeno en aire espirado con glucosa o lactulosa tritiada. Existen dos mecanismos que subyacen al desarrollo de la diarrea diabética. El primero es el menor transporte de fluidos a través de las vellosidades intestinales por menor estímulo alfa 2 adrenérgico, y el segundo es el tránsito intestinal enlentecido por sobrecrecimiento bacteriano (síndrome de asa ciega).

Para diferenciar los distintos mecanismos como método de diagnóstico, se utiliza el test de hidrógeno en aire espirado con glucosa o lactulosa tritiada lo que permite diferenciar si el tránsito está enlentecido o acelerado, y de este modo tratarlo de forma adecuada ${ }^{39}$.

Además existen otros factores etiológicos a considerar en este tipo de diarrea persistente, como el tránsito intestinal rápido, sobrecrecimiento bacteriano, uso de medicamentos (por ejemplo, metformina, acarbosa, miglitol), sustitutos del azúcar, enfermedad celíaca, insuficiencia pancreática, tumor de células de islote $u$ otras diarreas no asociadas a diabetes ${ }^{39}$.

\section{Tratamiento}

La neuropatía del aparato digestivo puede involucrar cualquier porción del tracto gastrointestinal, por lo tanto el tratamiento debe dirigirse a las manifestaciones clínicas presentes.

Dada la acción del nivel de glucemia sobre el tubo digestivo, la optimización del control glucémico debe ser el punto principal del tratamiento de la complicación de la neuropatía autonómica.

\section{Esófago}

La enfermedad de reflujo gastroesofágico puede tratarse efectivamente con medidas terapéuticas convencionales dirigidas a modificar esta condición. Solamente en aquellos pacientes refractarios estarían reservadas a las cirugías antireflujo.

La candidiasis esofágica se presenta más frecuentemente en pacientes con mal control glucémico; la dismotilidad favorece la presencia de la cándida. La estrategia principal es buscar el mejor control glucémico posible y específicamente el uso de antifúngicos orales como el fluconazol. La disfagia sintomática, sin embargo, es de más difícil manejo, especialmente si existe en presencia de ND motora avanzada, por lo tanto el diagnóstico temprano es importante porque en este estadio la condición es reversible ${ }^{39}$.

\section{Estómago}

Las consideraciones terapéuticas dependen de la severidad de los síntomas, de la habilidad del paciente de mantener una nutrición adecuada y de la respuesta al tratamiento.

Como la hiperglucemia puede enlentecer el vaciamiento gástrico, el control glucémico debería ser lo más cercano a la normalidad ${ }^{40}$.

Actualmente distintos medicamentos que mejoran la glucemia pueden actuar sobre la motilidad gástrica como los análogos de amilina (pramlintide) o los agonistas del receptor del GLP-1 (exenatide y liraglutide) que producen enlentecimiento del vaciamiento gástrico ${ }^{41,42,43}$ y los inhibidores de DPP-4 (sitagliptina y vildagliptina) que no retrasan la evacuación gástrica ${ }^{44}$.

Siempre hay que tener en cuenta el uso de otros medicamentos que modifican la motilidad, como los antihipertensivos (bloqueantes cálcicos, clonidina) o anticolinérgicos (antidepresivos), entre otros ${ }^{45}$.

En el compromiso leve el objetivo del tratamiento es mantener una adecuada alimentación 
por vía oral. En la gastroparesia severa podría requerirse la alimentación total o suplementaria por vía enteral o parenteral, siendo necesaria su asistencia en un centro de mayor complejidad ${ }^{46,47,48}$.

Las recomendaciones dietarias consisten en la masticación adecuada, administrar pequeños volúmenes de comida más frecuentes, bajos en grasas y en fibra. Las ingestas pueden ser de consistencia líquida, teniendo en cuenta que la mala tolerancia a la dieta líquida predice fracaso con la alimentación oral.

Los líquidos con elevada densidad energética en pequeños volúmenes permiten administrar energía y nutrientes sin exacerbar los síntomas. Deben evitarse las bebidas carbonatadas que agravan la distención gástrica, y el alcohol y el tabaco porque modifican la evacuación gástrica 49,50,51.

El ejercicio para el control del peso puede ser beneficioso para los pacientes con gastroparesia.

\section{Tratamiento farmacológico}

Además de la dietoterapia debe agregarse la terapia proquinética con el objetivo de mejorar el vaciamiento gástrico y los síntomas de gastroparesia, teniendo siempre presente los riesgos y beneficios del tratamiento.

- Metoclopramida. Es un antagonista del receptor de dopamina tipo 2 (D2), evidencia B. Es el único fármaco aprobado por la FDA para el tratamiento de la gastroparesia por un período no mayor de 12 semanas a menos que los beneficios terapéuticos superen los potenciales riesgos ${ }^{52}$. Debe administrarse en la menor dosis efectiva mínima en una formulación líquida para facilitar la absorción (dosis: 5-40 mg).

- Domperidona. Cuando no puede utilizarse la metoclopramida, la FDA prescribe la domperidona como nueva droga en investigación. Es igual de eficaz pero con menos efectos adversos del sistema nervioso central (SNC); el inconveniente es que tiene el riesgo de prolongación de QT con la presentación de arritmias cardíacas por lo que se sugiere un seguimiento electrocardiográfico regular (dosis: 10-60 mg) ${ }^{46}$.

- Eritromicina. Es agonista de la motilina. Tiene efectividad en forma intravenosa (dosis $3 \mathrm{mg} /$ peso cada 8 h). Se usa durante cuatro semanas por el peligro de taquifilaxia. Puede administrarse por vía oral por varias semanas. También prolonga el QT.

- Tratamiento sintomático de las náuseas, vómitos y el dolor. Las más prescriptas son la fe- notiazina o los agentes antihistamínicos como la prometazina, sin embargo producen prolongación del QT y no son efectivas en el vaciamiento gástrico. Recomendación condicional, nivel de evidencia moderado.

No existen evidencias que el ondansetrón sea superior a la metoclopramida y prometazina para reducir las náuseas en adultos ${ }^{53,54,55}$.

El dronabinol es un carabinoide sintético que se utiliza en la práctica pero tiene hiperémesis de rebote al suspenderse ${ }^{56}$.

La escopolamina transdérmica es efectiva en la náuseas asociadas a la cinetosis; se utiliza para las náuseas y vómitos de gastroparesia pero no existen trabajos que lo avalen ${ }^{57}$.

Los tricíclicos pueden considerarse para náuseas y vómitos refractarios pero dados sus efectos anticolinérgicos, pueden retardar aún más el vaciamiento gástrico.

De las terapias alternativas para náuseas y vómitos, la acupuntura es la más estudiada con evidencias de mejoría ${ }^{57}$.

\section{Tratamiento no farmacológico}

- Toxina botulínica. La inyección intrapilórica de toxina botulínica podría disminuir el piloroespasmo asociado a gastroparesia y por consiguiente reducir los síntomas. Existen estudios que demuestran mejoría del vaciamiento gástrico pero que no se acompaña con mejoramiento de los síntomas, por lo cual no está recomendado como tratamiento y se necesitan más estudios. Nivel de evidencia alto ${ }^{40}$.

- Estimulación eléctrica gástrica. Puede considerarse como tratamiento compasivo en pacientes con GP refractaria con náuseas y vómitos frecuentes; su uso disminuiría la frecuencia de vómitos semanales permitiendo reducir o suspender la alimentación enteral o parenteral. Nivel de evidencia moderada $\mathrm{B}^{40}$.

- Métodos quirúrgicos. En pacientes que no responden a tratamientos convencionales puede considerarse la gastroyeyunostomía para alimentación enteral. Debe realizarse en centros especializados dada su complejidad. Previo a la gastroyeyunostomía puede intentarse un ensayo con sonda naso-enteral. La indicación de alimentación enteral se realiza con la pérdida del $10 \%$ del peso habitual de tres a seis meses y/o hospitalizaciones repetidas por síntomas refractarios. La alimentación debe ser pospilórica para asegurar un suministro de nutrientes y la enteral siempre es preferible a la parenteral ${ }^{40}$. 
El tratamiento del compromiso intestinal apunta a los síntomas más relevantes que son la diarrea y la constipación.

- Diarrea. Si bien la constipación es el síntoma más frecuente entre pacientes con compromiso $\mathrm{GI}$, la diarrea es la más relevante porque afecta la calidad de vida de los mismos.

Como existen dos mecanismos que subyacen al desarrollo de la diarrea diabética, una vez hecho el diagnóstico si el tránsito está enlentecido o acelerado, debe tratarse el primero con antibióticos rifampicina y neomicina, y en caso de tránsito acelerado con agentes antimotilidad convencionales como la loperamida ${ }^{26}$.

- Constipación. En caso de tránsito lento la preferencia es usar laxantes osmóticos. Recientemente se utiliza el pucalopride (agonista de 5-HT4).

- Linaclotide: es una nueva droga que no se absorbe y se usa tanto en constipación como en síntomas de colon irritable.

- Piridostigmina: es un inhibidor de la colinesterasa que demostró acelerar el tránsito colónico y mejorar la función intestinal en algunos pacientes. Como el mecanismo involucrado en la génesis del dolor visceral compromete vías ascendentes y descendentes del SNC, esto justifica el uso de medicamentos con acción central como los antidepresivos tricíclicos a bajas dosis y opioides. Es necesario seguir investigando los mecanismos específicos de la causa del dolor para su mejor terapéutica.

En definitiva, un porcentaje de la población general presenta diferente grados de manifestaciones gastrointestinales, sin embargo cuando estos síntomas se manifiestan en pacientes diabéticos, la NA gastrointestinal debe considerarse e investigarse para un abordaje terapéutico adecuado.

\section{3) Síndrome de boca ardiente y neuropatía autonómica diabética}

Existe evidencia que describe cambios en la salud oral de los pacientes diabéticos con mal control glucémico. La periodontitis es la más frecuente de las complicaciones odontológicas en DM. Existen otras manifestaciones orales como boca seca, síndrome de boca ardiente y disgeusia, así como neuralgia trigeminal y trastornos en la articulación temporomandibular. Actualmente el manejo diabetológico en relación a la salud bucal a menudo es desestimado a pesar de las recomendaciones $58,59,60,61,62$.

El paciente suele no hacer referencia a su mé- dico de alguna alteración en la cavidad oral a menos que cause dolor, sangrado u otros síntomas.

Se mencionarán las diferentes manifestaciones orales asociadas a neuropatía diabética, con foco en el síndrome de la boca ardiente (SBA) como causa secundaria a la misma.

\section{Síndrome de boca ardiente}

Se define el síndrome de boca ardiente (SBA) como una enfermedad crónica dolorosa, caracterizada por ardor y hormigueo en la cavidad oral sin causa orgánica aparente en la forma primaria de presentación. Puede acompañarse de disgeusia y xerostomía; involucra a la lengua con o sin extensión de los labios y mucosa oral ${ }^{63,64}$. Puede presentarse de manera espontánea con una clara predisposición en mujeres peri y postmenopáusicas. Sus formas secundarias se asocian con diferentes patologías: tiroideopatías, enfermedades psiquiátricas, patologías orales, uso de dogas, tratamientos orales, déficit de vitaminas, y otras ${ }^{65,66}$.

\section{Fisiopatología}

La fisiopatología del SBA no está totalmente comprendida aún. Originalmente se consideraba una enfermedad psicogénica, pero actualmente se sospecha que su origen es neuropático. Esto se basa en anormalidades medidas objetivamente de respuestas fisiológicas del nervio trigémino en pacientes con SBA ${ }^{67,68}$. También existe evidencia de que hay cambios histopatológicos en las fibras nociceptivas de estos pacientes ${ }^{69}$.

La xerostomía en el SBA está probablemente relacionada a la neuropatía más que a alguna disfunción glandular y se asocia con una alta incidencia de enfermedades gastrointestinales y urogenitales lo cual aún es poco claro ${ }^{70}$.

\section{Manifestaciones clínicas}

El típico paciente con SBA es una mujer peri o post-menopaúsica con varias comorbilidades médicas, que se queja de la triada clásica de inflamación de la mucosa oral: dolor, disgeusia y xerostomía; en casi dos tercios de los casos no presenta una enfermedad visible en la cavidad oral por cuatro a seis meses de duración. Algunos pacientes pueden ser oligosintomáticos (dolor y disgeusia o xerostomía) o monosintomáticos ${ }^{71}$.

- Dolor (glosodinia). Es la típica manifestación. El dolor se describe como ardor, calor, hormigueo y entumecimiento. Es bilateral, compromete los 
dos tercios de la región anterior de la lengua o sólo la punta. La mucosa del paladar duro y los labios pueden estar involucrados. La mucosa bucal y el piso de la boca son sitios atípicos. En los pacientes con prótesis dentales, las crestas alveolares son sitios comunes ${ }^{72}$

En el estudio Pittsburgh de complicaciones en DM1 la asociación entre SBA y neuropatía fue significativa ${ }^{73}$. Dicho síndrome se diagnosticó en el $10 \%$ de los diabéticos con neuropatía y manifestaciones orales ${ }^{74}$. Arap et al. examinaron un estudio de casos y controles (DM2 N: 29; no diabéticos: 29) donde todos los participantes del estudio tenían complicaciones dolorosas neuropáticas con síntomas orales y signos sensitivo motores faciales; más de la mitad manifestó dolor $(55 \%)$ y un $17 \%$ experimentó SBA, como un posible indicador de neuropatía diabética dolorosa orofacial ${ }^{75}$. Sin embargo, un análisis multivariado no reveló neuropatía diabética como un predictor de glosodinia ${ }^{76}$.

- Disgeusia. Las alteraciones pueden tomar forma de disminución en la percepción de lo dulce o sensación intensificada de los sabores dulces y agrios. Puede presentarse como una forma persistente de un gusto o percepción alterada de los gustos. Los gustos persistentes pueden ser amargos, metálicos o una mezcla de ambos. La alteración del sabor ocurre frecuentemente en pacientes con diabetes como consecuencia de la hiposalivacion ${ }^{77}$ y posiblemente debido a neuropatía de los nervios sensitivos del gusto o microangiopatía que involucra las papilas gustativas ${ }^{78}$. En un estudio de Abassi en pacientes con DM1, el umbral del sabor aumentó con la severidad de la neuropatía, en especial de tipo autonómica ${ }^{79}$.

En otro estudio, entre 50 pacientes con diagnóstico reciente de DM1 y 50 personas sanas, se encontró que ambas NA y NP estarían asociadas con el alto grado de disgeusia, en especial en DM1 antes de iniciar el tratamiento antihiperglucemiante ${ }^{77}$.

Algunos autores creen que la degeneración de la sensación del gusto fue particularmente causada por neuropatía periférica que afecta el nervio del gusto y por microangiopatía de las papilas gustativas. Después de un examen de electrogustometría, a un tercio de 11 pacientes con DM1 y al 40\% de 72 pacientes con DM2 se les diagnosticó hipogeusia; además se diagnosticó ageusia completa al 3 y al $8 \%$ respectivamente ${ }^{80}$. En otro estudio, 73 ancianos rusos con DM2 fueron evaluados para la percepción del sabor dulce y se observó que estaba reducida e interpretaron dicha manifestación oral como neuropatía diabética ${ }^{81}$.

- Xerostomía. Se define como una sensación de sequedad oral, mientras que hiposalivación es la disminución del flujo de saliva. La mayoría de los pacientes experimenta xerostomía cuando la secreción de saliva se encuentra disminuida a la mitad de lo normal. Una de las consecuencias de la hiposalivación es el desarrollo de caries en localizaciones inusuales, periodontitis e infecciones orales (cándida), y dificultades en el gusto y el olfato al comer y hablar.

\section{Tratamiento}

Es importante antes de decidir el inicio de la terapia definir si el SBA es primario o secundario. Además de la diabetes son múltiples las causas de SBA secundario como anemia, candidiasis, déficit de vitamina $B$, hierro y folatos, hipotiroidismo o pénfigo, entre otras. El objetivo de la terapia en estos casos debe dirigirse a tratar la causa local o la enfermedad sistémica, y suspender la medicación desencadenante de los síntomas.

- Tratamiento no farmacológico. Debe optimizarse el control glucémico, suspender la medicación que pueda causar xerostomía, como anticolinérgicos o psicotrópicos, o reemplazar medicamentos que provoquen ardor oral, como antirretrovirales. En relación a las causas concomitantes anteriormente mencionadas se aconseja ajustar la dosis de levotiroxina, suplementar vitamina $B$, hierro, zinc, ácido fólico, realizar psicoterapia o acupuntura (estudios no controlados).

- Tratamiento farmacológico. Está dirigido a la neuropatía crónica; las drogas utilizadas son clonazepan (bajas dosis), ácido alfa-lipoico, capsaicina oral, capsaicina tópica, terapia de reemplazo hormonal, SSRIs, antidepresivos tricíclicos, lidocaína oral, irradiación cercana al ganglio estelar (para inhibir la descarga simpática y mejorar el flujo sanguíneo en la lengua), topiramato y olanzapina ${ }^{82}$.

En una revisión de Miziara et al. de estudios acerca del tratamiento en SBA idiopático, se sugiere el clonazepan tópico ya que se observó una mejoría a corto plazo; otros estudios con ácido alfa lipoico y terapia cognitiva también mostraron efectividad ${ }^{83}$. Menciona, además, como tratamiento el aloe vera tópico como protector de traumas reiterados de la mucosa oral83. Son pocos los estudios controlados realizados que respalden la efectividad, tolerabilidad y la persistencia de la respuesta terapéutica 
para los tratamientos aplicados en pacientes con SBA. Se requiere mayor información de diferentes aspectos, en especial en relación a la etiopatogenia y como resultado, su manejo terapéutico.

El análisis de la bibliografía demuestra una alta prevalencia de varias condiciones bucales que influyen negativamente en la calidad de vida de los individuos. Tanto los pacientes diabéticos como el equipo de salud que los contiene suelen desconocer la susceptibilidad a padecer patologías como SBA, gingivitis, periodontitis, pérdida de dientes o sequedad bucal, entre otras condiciones de salud bucal, y en consecuencia puede pasar desapercibida la necesidad de realizar exámenes, atención preventiva y terapéutica de la misma.

Se desconoce si el control de la salud bucal mejora la neuropatía, pero se determinó que el descenso de la glucemia luego del tratamiento periodontal mejora la neuropatía asociada a la hiperglucemia.

La colaboración interdisciplinaria médico-odontólogo debe ser estrecha. La investigación de la relación entre la neuropatía y la salud bucal es importante para lograr un beneficio en el estado general del paciente.

\section{4) Cistopatía diabética y neuropatía autonómica diabética}

Las complicaciones urológicas de la diabetes incluyen disfunción vesical diabética (DVD), disfunción sexual e infecciones del tracto urinario.

Existe una prevalencia muy variada por la falta de estandarización de los métodos diagnósticos para definir cistopatía diabética. Más de un 50\% de los hombres y mujeres con DM tiene disfunción vesical ${ }^{84}$. La poliuria y la hiperglucemia independientemente contribuyen a la patogénesis de la DVD. También se encuentra afectada la función de la vejiga lo que compromete el músculo, el nervio y el urotelio. La disfunción vesical refleja una condición progresiva que comienza con una pérdida de la inervación sensorio visceral relacionada con la severidad y duración de la neuropatía diabética, sin embargo no se ha hallado correlación con la retinopatía ${ }^{85}$.

Los síntomas de DVD suelen ser variados incluyendo la urgencia miccional y la variación en la frecuencia, nocturia e incontinencia. La DVD se caracteriza por un aumento en el residuo postmiccional (RPM) y en la capacidad de lleno vesical, con una disminución de la contractilidad de la misma.

Tradicionalmente la disfunción vesical diabéti- ca se define como una disminución de la sensación de la vejiga, aumento de la capacidad vesical y pobre vaciado de la misma; esto fue descripto por primera vez en el año 1976 por Frimodt Mo$\| r^{86}$. En un intento de definición más moderna habrá que incluir síntomas del tracto urinario inferior (STUI), hiperactividad vesical, disfunción miccional y retención urinaria ${ }^{87}$.

Los pacientes pierden la capacidad de registro $y$ "el deseo de orinar" que usualmente ocurre en sujetos sanos con el llenado de 300-400 ml85.

\section{Fisiopatología}

La patogénesis de la disfunción vesical en la diabetes es multifactorial. La cistopatía diabética se relaciona con la hiperglucemia prolongada, la cual induce una serie de cambios metabólicos dentro de las células, siendo el estrés oxidativo uno de los principales ${ }^{88}$.

El estrés oxidativo causa daño a las células del músculo liso e induce la apoptosis celular en la cistopatía diabética ${ }^{87}$; el aumento de éste interrumpe la supervivencia de las neuronas y acelera la neurodegeneración ${ }^{87}$.

La adaptación física a la poliuria conlleva la remodelación de la pared vesical incluyendo la hipertrofia, dilatación, aumento de la contractilidad y reorganización de las relaciones estructurales entre el detrusor, el urotelio y el colágeno ${ }^{87}$; en la fase tardía se produce una disminución de la presión de la micción y el aumento del volumen residual, por lo tanto, la poliuria altera la función de la vejiga en los diabéticos ${ }^{87}$.

En la fisiopatología debe tenerse en cuenta, además de los mecanismos comunes ya descriptos, el rol del músculo detrusor, del urotelio y la disfunción uretral.

\section{Rol del músculo detrusor}

Los cambios en la fisiología del músculo detrusor se atribuyen a mecanismos como: cambios en las conexiones intercelulares, excitabilidad, densidad y distribución de los receptores ${ }^{87}$. Sin embargo existen varias controversias con respecto al tiempo y magnitud de estos cambios porque la mayoría de las conclusiones se basa en estudios con relevancia desconocida para la fisiopatología humana.

Se ha descripto una respuesta mejorada a los agonistas muscarínicos en el músculo detrusor de los pacientes diabéticos, lo cual puede deberse a un aumento de los receptores (densidad) ${ }^{89}$. 
También la glucosuria y la diuresis osmótica conducen al aumento del estiramiento de la vejiga, con la siguiente elevación de la presión intravesical que favorece la hipertrofia vesical y tardíamente lleva al aumento del volumen residual y exacerba el estrés oxidativo ${ }^{89}$.

La vejiga descompensada muestra alteraciones de las características contráctiles como la expresión de los subtipos de los receptores muscarínicos y también de la composición de isoformas de miosina II90; quizás esto explica las respuestas aumentadas y prolongadas a un estímulo despolarizante en la vejiga hipertrofiada y proporciona una estrategia farmacológica para el tratamiento ${ }^{89}$. Sin embargo, es importante considerar que los estudios de los efectos de la diabetes sobre la contractilidad del detrusor han producido tanto aumento ${ }^{91,92}$ como disminución de la contractilidad ${ }^{93,94}$.

La activación de la vía de aldosa reductasa contribuye a la activación de la proteína kinasa $C$, una proteína de transducción de señales que se altera en algunos tejidos propensos a complicaciones de la diabetes ${ }^{89}$. La administración de un inhibidor de la aldosa reductasa a ratas diabéticas causó: a) mejora en los parámetros de cistometría tales como volúmenes de micción, fracción de micción y volumen residual; b) restauró la expresión genética del receptor p75NTR ${ }^{89}$. La proteína p75NTR es una de las dos clases de receptores de superficie celular del factor de crecimiento nervioso que se expresa en neuronas. Estos hallazgos son relevantes porque estas fibras nerviosas positivas a p75 han sido identificadas tanto en la vejiga humana como en las ratas ${ }^{89}$.

\section{Rol del urotelio}

El urotelio consta de al menos tres capas: basal, intermedia y capa apical o superficial (células sombrilla). La función de barrera de estas células se reconoce tempranamente. El urotelio es capaz de adaptarse a grandes variaciones en el volumen de orina mientras la vejiga se llena y vacía. A nivel celular, hay exocitosis y fusión de un grupo subapical de vesículas con las células superficiales (sombrilla) de la membrana plasmática apical para dar como resultado aumentos en el área superficial de la mucosa ${ }^{89}$. El urotelio también actúa como un sensor para controlar la función de la vejiga y en este sentido liberar mediadores que afectan a los nervios aferentes y por lo tanto relacionados con la disfunción de la vejiga diabética. El urotelio está cubierto con una capa de polisacáridos glucosaminoglucanos sulfatados que disminuye la adherencia bacteriana y actúa como un mecanismo de defensa no específico contra la infección ${ }^{89}$. Cuando se producen procesos locales (infecciones, traumatismos mecánicos y químicos) y no locales (lesión de la médula espinal) pueden interrumpir la barrera de función del urotelio y, como resultado, las sustancias tóxicas pueden generar síntomas de urgencia, frecuencia y dolor durante el llenado y el vaciado de la vejiga ${ }^{89}$. Estos eventos pueden potencialmente cambiar los niveles de mediadores químicos como el óxido nítrico (ON) y el ATP, que son importantes para la integridad epitelial y el funcionamiento adecuado ${ }^{95}$. La presencia de receptores P2X, P2Y en la superficie luminal de la vejiga sugieren el papel del ATP como sustancia comunicante en la función de la misma ${ }^{89}$.

Se ha demostrado un potencial papel fisiopatológico de fibras que expresan purina en sujetos humanos con hiperactividad del detrusor neurogénico. El urotelio y los nervios de la vejiga tienen muchos receptores y canales de iones en común, lo que implica que una lesión o inflamación puede alterar la respuesta tanto de las células uroteliales como de las aferentes sensitivas a estímulos nociceptivos y otros simultáneamente ${ }^{96}$.

El ON es sintetizado por una familia de enzimas conocidas como NOSs endotelial (eNOS), inducible (iNOS) y neuronal (nNOS). Hay activación de NOS en el urotelio, músculo liso, estriado, nervios y vasos sanguíneos del aparato urinario inferior tanto en humanos como en modelos animales. El efecto relajante de ON en el músculo detrusor se ha demostrado en estudios animales. Se conoce desde hace mucho tiempo que el ON puede tener un papel en la neurotransmisión no adrenérgica, no colinérgica en el tracto urinario inferior, una sugerencia que fue fortalecida por la evidencia inmunohistoquímica de la actividad NOS en los músculos estriados de los esfínteres uretrales humanos ${ }^{97}$. El compromiso de las vías ON dependientes y su rol en la disfunción de las vías urinarias puede ser objeto de nuevas intervenciones terapéuticas ${ }^{97}$.

\section{Disfunción uretral}

El almacenamiento y la liberación de orina requiere coordinación entre la vejiga urinaria y el esfínter uretral externo. Durante la progresión de la enfermedad, las neuronas aferentes uretrales son hiperexitables; la hiperglucemia prolongada provoca 
disfunción del esfínter uretral externo al aumentar la resistencia de salida, alterar la relajación del músculo liso uretral y la respuesta del óxido nítrico ${ }^{89}$.

\section{Papel del daño neuronal}

La hiperglucemia puede ejercer sus efectos tóxicos a través del daño neuronal; los posibles mecanismos para ello son la activación de la vía del polioles (que resulta en la acumulación de sorbitol y fructosa), aumento de la producción de radicales libres, activación de proteína kinasa $\mathrm{C}$ e incremento de los productos de glicación avanzada ${ }^{89}$. Estos trastornos metabólicos conducen a la degeneración axonal y deterioro de la conducción nerviosa, que más tarde se manifiesta como hiposensación de la vejiga. Una disminución de la actividad de la acetilcolinesterasa en las biopsias vesicales de los pacientes diabéticos puede deberse a la degeneración axonal y proliferación de células de Schwann; esto ocurre en un intento de causar regeneración después de la desmielinización o degeneración axonal ${ }^{98}$.

La disminución de la síntesis del factor de crecimiento nervioso en la vejiga, o el transporte defectuoso del factor de crecimiento nervioso a la región lumbosacra (ganglio de la raíz dorsal), se asocia con neuropatía diabética y disfunción vesical ${ }^{84}$. El factor de crecimiento nervioso (miembro de la familia del factor neurotrofina) es necesario para mantener la función normal de la sensibilidad, además de su capacidad para promover la supervivencia de las neuronas durante el desarrollo; 89 datos recientes también sugieren un papel de este factor en los procesos de inflamación y dolor ${ }^{99}$.

Además de la cistopatía, la neuropatía diabética también puede afectar otros órganos incluyendo el tracto gastrointestinal, lo que puede ocasionar estreñimiento, alteración de la sensibilidad rectal y/o incontinencia del esfínter anal interno; éstos son particularmente importantes porque pueden disminuir el rendimiento del tracto urinario ${ }^{89}$. La presión de la vejiga sobredistendida puede inhibir la actividad del reflejo parasimpático, siendo un estímulo para retención fecal. Por otro lado, el esfuerzo para defecar puede afectar los músculos del suelo pélvico y conducir a rectocele y cistocele (en mujeres), y un mayor riesgo de incontinencia por estrés y el vaciado incompleto de la vejiga ${ }^{89}$.

\section{CONCLUSIONES}

La prevención de la neuropatía diabética se enfoca en el control glucémico y en las modificacio- nes en el estilo de vida. La evidencia disponible es pertinente para la polineuropatía distal y simétrica, y la neuropatía autonómica².

La neuropatía autonómica diabética pareciera comprometer todos los órganos y sistemas de la economía, con distintos grados de afectación y manifestaciones clínicas que no siempre se tienen en cuenta.

Pensar en aquellas condiciones poco frecuentes, poco sintomáticas o confusas, varias veces atribuidas a otros factores causales y que, de alguna manera afectan la calidad de vida de los pacientes diabéticos con neuropatía, nos obliga al menos a investigarlas y tratarlas.

\section{BIBLIOGRAFÍA}

1. Ziegler D, Zentai CP, Perz S, et al.; KORA Study Group. Prediction of mortality using measures of cardiac autonomic dysfunction in the diabetic and nondiabetic population: the MONICA/KORA Augsburg Cohort Study. Diabetes Care 2008; 31:556-561.

2. Pop-Busui R, Feldman EL, Malik RA, Boulton AJ, Bril V, Freeman R, Sosenko JM, Ziegler D. Diabetic neuropathy: a position statement by the American Diabetes Association. Diabetes Care 2017;40:136-154.

3. Jin HY, Baek HS, Park TS. Morphologic changes in autonomic nerves in diabetic autonomic neuropathy. Diabetes Metab J 2015 Dec; 39(6):461-467. English. Review Published online December 11, 2015. https://doi.org/10.4093/dmj.2015.39.6.461

4. Actualización en disfunción sexual en pacientes diabéticos. Comité de Neuropatía Diabética de la Sociedad Argentina de Diabetes. Rev Soc Arg Diabetes 2013; 1: 29-39

5. Vinik A, Erbas T, Casellini CM. Diabetic cardiac autonomic neuropathy, inflammation and cardiovascular disease. J Diabetes Investig 2013 Jan 29; 4(1): 4-18.

6. Pop-Busui R, Cleary PA, Braffett BH, et al.; DCCT/EDIC Research Group. Association between cardiovascular autonomic neuropathy and left ventricular dysfunction: DCCT/EDIC study (Diabetes Control and Complications Trial/ Epidemiology of Diabetes Interventions and Complications). J Am Coll Cardiol 2013; 61:447-454.

7. Maser RE, Mitchell BD, Vinik Al, et al. The association between cardiovascular autonomic neuropathy and mortality in individuals with diabetes: a meta-analysis. Diabetes Care 2003; 26:1895-1901.

8. Pop-Busui R, Evans GW, Gerstein HC, et al.; Action to Control Cardiovascular Risk in Diabetes Study Group. Effects of cardiac autonomic dysfunction on mortality risk in the Action to Control Cardiovascular Risk in Diabetes (ACCORD) trial. Diabetes Care 2010; 33:1578-1584.

9. Young LH, Wackers FJ, Chyun DA, et al.; DIAD Investigators. Cardiac outcomes after screening for asymptomatic coronary artery disease in patients with type 2 diabetes: the DIAD study: a randomized controlled trial. JAMA 2009; 301:1547-1555.

10. Vinik A. Diabetic cardiovascular autonomic neuropathy. Circulation 2007; 115:387-397.

11. Stewart JM, et al. Clinical and physiological effects of an acute alpna- 1 adrenergic agonist and a beta- 1 adrenergic antagonist in chronic orthostatic intolerance. Circulation 2002; 106, 2946-2954. 
12. Raj SR. Renin-aldosterone paradox and perturbed blood volume regulation underlying postural tachycardia syndrome. Circulation 2005; 111:1574-1582.

13. Stewart JL. Increased plasma angiotensin II in postural tachycardia syndrome (POTS) is related to reduced blood flow and blood volumen. Clinical Science 2006; 110, 255-263.

14. Didangelos TP. Left ventricular systolic and diastolic function in normotensive type 1 diabetic patients with or without autonomic neuropathy. Diabetes Care 2003; 26:1955-1960.

15. Task Force of the European Society of Cardiology and the North American Society of Pacing and Electrophysiology. Heart rate variability: standards of measurement, physiological interpretation and clinical use. Circulation 1996; 93: 1043-1065.

16. Pop-Busui R. Cardiac autonomic neuropathy in diabetes: a clinical perspective. Diabetes Care 2010; 33:434-441.

17. Pop-Busui R, Low PA, Waberski BH, et al.; DCCT/EDIC Research Group. Effects of prior intensive insulin therapy on cardiac autonomic nervous system function in type 1 diabetes mellitus: the Diabetes Control and Complications Trial/Epidemiology of Diabetes Interventions and Complications study (DCCT/EDIC). Circulation 2009; 119:2886-2893.

18. Low PA, Benrud-Larson LM, Sletten DM, et al. Autonomic symptoms and diabetic neuropathy: a population-based study. Diabetes Care 2004; 27:2942-2947.

19. Ziegler D, Keller J, Maier C, et al.; German Diabetes Association. Diabetic neuropathy. Exp Clin Endocrinol Diabetes 2014;122: 406-415.

20. Freeman R. Clinical practice. Neurogenic orthostatic hypotension. N Engl J Med 2008; 358:615-624.

21. Spallone V, Bellavere F, Scionti L, et al.; Diabetic Neuropathy Study Group of the Italian Society of Diabetology. Recommendations for the use of cardiovascular tests in diagnosing diabetic autonomic neuropathy. Nutr Metab Cardiovasc Dis 2011; 21:69-78.

22. Low PA, Gilden JL, Freeman R, et al.; Midodrine Study Group. Efficacy of midodrinevs placebo in neurogenic orthostatic hypotension. A randomized, doubleblind multicenter study. JAMA 1997; 277:1046-1051.

23. Low PA, Tomalia VA. Orthostatic hypotension: mechanisms, causes, management. J Clin Neurol 2015; 11:220-226.

24. Folwaczny $C$, Riepl R, Tschöp M, et al. Gastrointestinal in volvement in patients with diabetes mellitus: Part I (first of two parts). Epidemiology, pathophysiology, clinical findings. Z Gastroenterol 1999; 37: 803-815.

25. Zhao J, Frøkjær JB, Drewes AM, et al. Upper gastrointestinal sensory-motor dysfunction in diabetes mellitus. World $\mathrm{J}$ Gastroenterol 2006 May 14; 12(18): 2846-2857. Disponible en: www.nature.com/clinicalpractice/gasthep.

26. Sellin J, Chang E. Therapy insight: gastrointestinal complications of diabetes pathophysiology and management. Nature Clinical Practice Gastroenterologic \& Hepatologis 2008; 5 (3): 162-171.

27. Tsai SC, Kao CH, Pan DY, et al. Effects oforal erythromycin on esophageal motility in patients with noninsulin-dependent diabetes mellitus. The Kaohsiung Journal of Medical Sciences 1995; 11: 430-435.

28. Annese V, Bassotti G, Caruso N, et al. Gastrointestinal motor dysfunction, symptoms, and neuropathy in noninsulindependent (type 2) diabetes mellitus. J Clin Gastroenterol 1999; 29: 171-177.

29. Holloway RH, Tippett MD, Horowitz M, et al. Relationship between esophageal motility and transit in patients with type 1 diabetes mellitus. Am J Gastroenterol 1999; 94: 3150-3157.
30. Björnsson ES, Urbanavicius V, Eliasson B, Attvall S, Smith U Abrahamsson $\mathrm{H}$. Effects of hyperglycemia on interdigestive gastrointestinal motility in humans. Scand J Gastroenterol 1994; 29: 1096-1104.

31. Samsom M, Jebbink RJ, Akkermans LM, van Berge-Henegouwen GP, Smout AJ. Abnormalities of antroduodenal motility in type I diabetes. Diabetes Care 1996; 19: 21-27.

32. Azpiroz F, Malagelada C. Diabetic neuropathy in the gut: pathogenesis and diagnosis. Diabetologia 2016; 59:404-408.

33. Yarandi SS, Srinivasan S. Diabetic gastrointestinal motility disorders and the role of enteric nervous system: current status and future directions. Neurogastroenterol Motil 2014; 26:611-624.

34. Malagelada C, Drozdzal M, Seguí S, et al. Classification of functional bowel disorders by objective physiological criteria based on endoluminal image analysis. Am J Physiol Gastrointest Liver Physiol 2015; 309:G413-G419.

35. Malagelada C, De lorio F, Azpiroz F, et al. New insight into intestinal motor function via non invasive endoluminal image analysis. Gastroenterology 2008; 135:1155-1162

36. Frøkjaer JB, Andersen SD, Ejskaer N, et al. Gut sensations in diabetic autonomic neuropathy. Pain 2007; 131:320-329.

37. Azpiroz F. Gastrointestinal perception: pathophysiological implications. Neurogastroenterol Motil 2002; 14:229-239.

38. Distrutti E, Azpiroz F, Soldevilla A, et al. Gastric wall tension determines perception of gastric distention. Gastroenterology 1999; 116: 1035-1042.

39. Sellin J, Chang E. Therapy insight: gastrointestinal complications of diabetes pathophysiology and management. Nature Clinical Practice Gastroenterology \& Hepatology 2008; 5 (3): 162-171.

40. Camilleri M, Parkman H. Clinical guideline: management of gastroparesis. Am J Gastroenterol 2013; 108(1): 18-38.

41. Camilleri $M$, Buéno $L$, et al. Pharmacologic, pharmacokinetic, and pharmacogenomic. Aspects of functional gastrointestinal disorders. Gastroenterology 2016; 150:1319-1331.

42. Poen AC, Felt-Bersma RJ, Van Dongen PA, et al. Effect of prucalopride, a new enterokinetic agent, on gastrointestinal transit and anorectal function in healthy volunteers. Aliment PharmacolTher 1999: 13:1493-1497.

43. Degen L, Matzinger D, Merz M, et al.Tegaserod, a 5-HT4 receptor partial agonist, accelerates gastric emptying and gastrointestinal transit in healthy male subjects. Aliment Pharmacol Ther 2001; 15:1745-1751.

44. Cremonini F, Delgado-Aros S, Camilleri M. Efficacy of alosetron in irritable bowel syndrome: a meta-analysis of randomized controlled trials. Neurogastroenterol Motil 2003; 15:79-86.

45. Camilleri M. Diabetic gastroparesis. N Engl J Med 2007; 356:820-829.

46. Panel nacional de expertos sobre la atención de gastroparesia ALAD. Rev ALAD 2017; 7: 9-23

47. Camilleri M. Appraisal of medium-and long-term treatment of gastro paresis and chronic intestinal dysmotility. Am J Gastroenterol 1994; 89:1769-1774.

48. AbellTL, Bernstein VK, CuttsT, et al. Treatment of gastroparesis: a multidisciplinary clinical review. Neurogastroenterol Motil 2006; 18:263-283.

49. Pfeiffer A, Holgl B, Kaess H. Effect of ethanol and commonly ingested alcoholic beverages on gastric emptying and gastrointestinal transit. Clin Investig 1992; 70:487-491.

50. Sanaka M, Anjiki H, Tsutsumi $H$, et al. Effect of cigarette smoking on gastric emptying of solids in Japanese smokers: a crossover study using the $13 \mathrm{C}$-octanoic acid breath test. J Gastroenterol 2005; 40:578-582. 
51. Scott AM, Kellow JE, Eckersley GM, et al. Cigarette smoking and nicotine delay postprandial mouth-cecum transit time. Dig Dis Sci 1992; 37:1544-1547.

52. Cho YK, Choi MG, Park EY, et al. Effect of mosapride combined with esomeprazole improves esophageal peristaltic function in patients with gastroesophageal reflux disease: a study using high resolution manometry. Dig Dis Sci 2013; 58:1035-1041.

53. Owczuk R, Twardowski P, Dylczyk-Sommer A, et al. Influence of promethazine on cardiac repolarisation: a double-blind, midazolam-controlled study. Anaesthesia 2009; 64:609-614. PubMed: 19453313.

54. Patanwala AE, Amini R, Hays DP, et al. Antiemetic therapy for nausea and vomiting in the emergency department. J Emerg Med 2010; 39: 330-336. PubMed: 20022195.

55. Barrett TW, Di Persio DM, Jenkins CA, et al. A randomized, placebo-controlled trial of ondansetron, metoclopramide, and promethazine in adults. Am J Emerg Med 2011; 29:247-255.

56. Allen JH, de Moore GM, Heddle R, et al. Cannabinoid hyperemesis: cyclical hyperemesis in association with chronic cannabis abuse. Gut 2004; 53:1566-1570.

57. Wang L. Clinical observation on acupuncture treatment in 35 cases of diabetic gastroparesis. J Tradit Chin Med 2004; 24: 163-165. PubMed: 15510787.

58. Borgnakke WS, Ylöstalo PV, et al. Effect of periodontal disease on diabetes: systematic review of epidemiologicobservational evidence. J Periodontol 2013; 84:S135-52. Doi:10.1902/ jop.2013.1340013.

59. Borgnakke WS. Hyperglycemia/diabetes mellitus and periodontal infection adversely affect each other. In: Genco RJ, Williams RC, editors. Periodontal disease and overall health: A clinician's guide. $2^{\circ}$ Ed. Yardley, PA: Professional Audience Communications; 2014, 99-122. Disponible en: http://www.Colgateprofessional.Com/professionaleducation/articles/periodontal-disease-and-overall-healtha-clinicians-guide-secondedition. Accessed: August 22, 2015.

60. Borgnakke W. Does treatment of periodontal disease influence systemicdisease? Dent Clin North Am 2015; 59(4):n/a. Doi:10.1016/j.cden.2015.06.007.

61. Borgnakke WS, Chapple IL, Genco RJ, et al. The multi-center randomized controlled trial (RCT) published by the Journal of the American Medical Association (JAMA) on the effect of periodontal therapy onglycated hemoglobin $(\mathrm{HbA} 1 \mathrm{c})$ has fundamental problems. J Evid Based Dent Pract 2014; 14:127-32. Doi:10.1016/j.jebdp.2014.04.017.

62. American Diabetes Association. Initial evaluation and diabetes management planning. Diabetes Care 2015; 38:S17-9. Doi:10.2337/dc15-S006.

63. Netto FO, Diniz IM, Grossmann SM, et al. Risk factors in burning mouth syndrome: a case-control study based on patient records. Clin Oral Investig 2011; 15: 571-575. PMID: 20440632.

64. Lamey PJ, Lamb AB. Prospective study of aetiological factors in burning mouth syndrome. Br Med J (Clin Res Ed) 1988; 296: 1243-1246. PMID: 3133028.

65. Yilmaz $Z$, Renton T, Yiangou Y, et al. Burning mouth syndrome as a trigeminal small fibre neuropathy: increased heat and capsaicin receptor TRPV1 in nerve fibres correlates with pain score. J Clin Neurosci 2007; 14: 864-871. PMID: 17582772.

66. Grushka M, Epstein JB, Gorsky M. Burning mouth syndrome: differential diagnosis. Dermatol Ther 2002; 15287-291. Doi: 10.1046/j.1529-8019.2002.01535.

67. Forssell $\mathrm{H}$, Jaaskelainen $\mathrm{S}$, Tenovuo $\mathrm{O}$, et al. Sensory dysfunction in burning mouth syndrome. Pain 2002 Sep 99; (1-2): 41-7.
68. Grushka M, Sessle BJ, Howley TP. Psychophysical assessment of tactile, pain and thermal sensory functions in burning mouth syndrome. Pain $1987 \mathrm{Feb}$; 28(2):169-84.

69. Beneng $K$, Yilmaz $Z$, Yiangou $Y$, et al. Sensory purinergic receptor P2X(3) is elevated in burning mouth syndrome. Int J Oral Maxillofac Surg 2010 Apr 24; 815-819.

70. Friedman DI. Topirimate-induced burning mouth syndrome. Headache 2010 Sep; 50(8):1383-5.

71. Scala A, Checchi L, Montevecchi M, et al. Update on burning mouth syndrome: overviewand patient management. Crit Rev Oral Biol Med 2003; 14:275-291. PMID: 12907696.

72. Eusterman VD. Burning mouth syndrome updated. Chief Editor: Arlen D Meyers Feb 07, 2017.

73. Moore PA, Guggenheimer J, Orchard T. Burning mouth syndromeand peripheral neuropathy in patients with type 1 diabetes mellitus. J Diabetes Complicat 2007; 21: 397-402. Doi:10.1016/j. jdiacomp.

74. Bajaj S, Prasad S, Gupta A, Singh VB. Oral manifestations in type 2 diabetes and related complications. Indian J Endocrino Metab 2012;16:777-9. Doi:10.4103/2230-8210.100673.

75. Arap A, Siqueira SR, Silva CB, et al. Trigeminal pain and quantitative sensory testing in painful peripheral.diabetic neuropathy. Arch Oral Biol 2010; 55:486-93. Doi:10.1016/j.archoralbio.2010.03.021.

76. Collin HL, Niskanen L, Uusitupa M, et al. Oral symptoms and signs in elderly patients with type 2 diabetes mellitus. A focus on diabetic neuropathy. Oral Surg Oral Med Oral Pathol Oral Radiol Endod 2000; 90 (3):299-305. Doi:10.1067/moe.2000.107536.

77. Le Floch JP, Le Lievre G, Verroust J, et al. Factors related to the electric taste threshold in type 1 diabetic patients. Diabet Med 1990; 7:526-31. Doi:10.1111/j.1464-5491.1990.tb01436.x.

78. Le Floch JP, Le Lievre G, Labroue M, et al. Early detection of diabetic patients at risk of developing degenerative complications using electric gustometry: a five-year follow-up study. Eur J Med 1992; 1:208-14.

79. Abbasi AA. Diabetes: diagnostic and therapeutic significance oftaste impairment. Geriatrics 1981; 36:73-4.

80. Stolbova K, Hahn A, Benes B, et al. Gustometry of diabetes meIlitus patients and obese patients. Int Tinnitus J 1999; 5:135-40.

81. Fomina El, Pozharitskaia MM, Davydov AL, et al. Changes of gustatory perception inelderly patients with type II sugar diabetes. Surgical section. Russian. Stomatologia (Mosk) 2007; 86:30-4.

82. Eusterman VD. Burning mouth syndrome updated. Chief Editor: Arlen D Meyers Feb 07, 2017.

83. Miziara I, Chagury A, Vargas C, et al. Therapeutic options in idiopathic burning mouth syndrome: literature review. Int Arch Otorhinolaryngol 2015 Jan; 19 (1):86-9.

84. Brown JS, Wessells $\mathrm{H}$, Chancellor MB, et al. Urologic complications of diabetes. Diabetes Care 2005 Jan; 28(1):177-85.

85. Kebapci N, Yenilmez A, Efe B, et al. Bladder dysfunction in type 2 diabetic Patients. Neurourol Urodyn 2007; 26(6):814-9.

86. Moller CF, Olesen KP. Diabetic cystopathy. IV: Micturition cystourethrography compared with urodynamic investigation. Dan Med Bull 1976 Dec; 23 (6): 291-4.

87. Yuan Z, Tang Z, He C, et al. Diabetic cystophaty: a review. J Diabetes 2015 Jul; 7(4):442-7. Doi: 10.1111/1753-0407.12272. Epub 2015 Mar 24. Review.

88. Liu G, Daneshgari F. Diabetic bladder dysfunction. Chin Med J (Engl). 2014; 127(7):1357-64. Review. 
89. Golbidi S, Laher I. Bladder dysfunction in diabetes mellitus. Front Pharmacol 2010 Nov 16; 1:136.

90. Peters SL, Schmidt M, Michel MC. Rho kinase: a target for treating urinary bladder dysfunction? Trends Pharmacol Sci 2006; 27, 492-497.

91. Tammela L, Briscoe JA, Levin RM, et al. Factors underlying the increased sensitivity to field stimulation of urinary bladder strips from streptozotocin-induced diabetic rats. Br J Pharmacol 1994; 113,195-203.

92. Waring JV, Wendt IR. Effects of streptozotocin-induced diabetes mellitus on intracellular calcium and contraction of longitudinal smooth muscle from rat urinary bladder. J Urol 2000; $163,323-330$.

93. Changolkar AK, Hypolite JA, Disanto M, et al. Diabetes induced decrease in detrusor smooth muscle force is associated with oxidative stress and overactivity of aldose reductase. J Urol 2005; 173, 309-313.
94. Daneshgari F, Liu G, Birder L, et al. Diabetic bladder dysfunction: current translational knowledge. J Urol 2009; 182,S18-S26.

95. Apodaca G, Kiss S, Ruiz W, et al. Disruption of bladder epithelium barrier function after spinal cord injury. Am J Physiol Renal Physiol 2003; 284, F966-F976.

96. Yoshimura N, Chancellor MB, Andersson KE, et al. Recent advances in understanding the biology of diabetes-associated bladder complications and novel therapy. BJU Int 2005; 95, 733-738.

97. Mamas MA, Reynard JM, Brading AF. Nitric oxide and the lower urinary tract: current concepts, future prospects. Urology $2003 ; 61,1079-1085$.

98. Van Poppel H, Stessens R, Van Damme B, et al. Diabetic cystopathy: neuropathological examination of urinary bladder biopsies. Eur Urol 1998; 15, 128-131.

99. Steers WD, Tuttle JB. Mechanisms of disease: the role of nerve growth factor in the pathophysiology of bladder disorders. Nat Clin Pract Urol 2006; 2, 101-110.

\section{Fe de erratas}

En la Revista de la Sociedad Argentina de Diabetes, Vol. 52, № 1, Abril de 2018, en el artículo "Tratamiento de la enfermedad hepática grasa no alcohólica" (págs. 10-24) los autores olvidaron realizar las siguientes aclaraciones:

- En la página 10 faltó agregar como autora a la Dra. Guadalupe Vanoli (Médica especialista en Nutrición, Médica de Planta de la Unidad de Nutrición y Diabetes del Hospital General de Agudos "José María Ramos Mejía", Ciudad Autónoma de Buenos Aires, Argentina).

- En la página 10 a la Dra. Victoria Salinas le corresponden los siguientes datos afiliatorios: Médica especialista en Clínica y Nutrición, integrante del Departamento de Clínica Médica y Nutrición de CEMIC, Ciudad Autónoma de Buenos Aires, Argentina.
- En la página 15, segunda columna, línea 22, donde dice: "Los análogos del GLP-1 son producidos por las células $L$ del intestino delgado en respuesta a los nutrientes que llegan a esa porción del tubo digestivo" debió decir: "El análogo del GLP-1 es producido por las células $L$ del intestino delgado en respuesta a los nutrientes que llegan a esa porción del tubo digestivo"

- En la página 16, segunda columna, línea 24, donde dice: "Los efectos beneficiosos adicionales incluyen: bajo riesgo de hipoglucemia, pérdida de peso a expensas de la masa magra y disminución de la presión arterial", debió decir: "Los efectos beneficiosos adicionales incluyen: bajo riesgo de hipoglucemia, pérdida de peso a expensas de la masa grasa y disminución de la presión arterial". 